\title{
CRÍTICA E PATOLOGIA SOCIAL: AMBIVALÊNCIAS DA RELAÇÃO ENTRE PSICANÁLISE E TEORIA SOCIAL
}

\author{
Filipe Campello \\ Universidade Federal do Pernambuco
}

"Na psicanálise, nada é verdadeiro, a não ser seus exageros"

$(\text { Adorno })^{1}$

Resumo: Com o enfoque na apropriação da psicanálise no contexto da teoria crítica, o presente artigo discute possíveis ambivalências na conexão entre conceitos psicanalíticos e a teoria social. Para tanto, desdobro a exposição em quatro passos. Inicialmente, pretendo mostrar como Adorno, ao mesmo tempo que encontra em Freud as vantagens de uma perspectiva de descentramento do sujeito, também expõe a crítica a um possível inflacionamento de categorias psicanalíticas no âmbito da sociologia (1). A partir dessa breve reconstrução, discuto em que medida o vínculo entre categorias psicanalíticas e sociais pode permanecer produtivo, considerando o problema do estatuto epistemológico da psicanálise (2). Em um terceiro passo, apresento, de forma sucinta, a recente interlocução com a psicanálise proposta por Axel Honneth, sugerindo que conceitos como reconhecimento e patologia social apontam para um sentido específico de limites à uma teoria social (3). Concluo sugerindo uma distinção entre três sentidos de sofrimento e terapia, cuja tipologia exemplifica de maneira paradigmática uma delimitação recíproca entre psicanálise e teoria social (4).

Palavras-chave: Reconhecimento, Patologia, Teoria Crítica, Psicanálise.

\begin{abstract}
Highlighting the appropriation of psychoanalysis in the context of critical theory, the present paper discusses the ambivalences in the relation between psychoanalytic concepts and social theory. Therefore, I develop my argument in four steps. Initially, I intend to show how Adorno, at the same time that he finds in Freud the advantages of a perspective of a decentered subjectivity, he also develops a critique of a possible inflating of psychoanalytic categories in sociological field (1). In view of this brief reconstruction, I discuss to what extent the link between psychoanalytic and social categories can stay productive, considering the problem of the epistemological status of psychoanalysis (2). In a third step, I briefly present the recent interlocution with psychoanalysis proposed by Axel Honneth, suggesting that concepts such as recognition and social pathology point to a specific sense of limits to a social theory (3). Finally, I conclude by suggesting a distinction between three meanings of suffering and therapy, the typology of which exemplifies paradigmatically a reciprocal delimitation between psychoanalysis and social theory (4).
\end{abstract}

Keywords: Recognition, Social Pathologies, Critical Theory, Psychoanalyses.

${ }^{1}$ ADORNO, 1993, p.41.

C Dissertatio [46] 3-23 | 2017 
Já no seu início, a teoria psicanalítica teve como escopo não só o delineamento de uma teoria da subjetividade, mas também possíveis aplicações de seus conceitos no âmbito de um diagnóstico social. É notadamente em escritos como Psicologia das Massas e a Análise do Eu e, mais enfaticamente, em $O$ Mal-estar na civilização, onde encontramos a preocupação de Freud em compreender relações sociais a partir de categorias psicanalíticas. O que se percebe, aqui, é não só a premissa da indissociabilidade entre sujeito e sociedade, como também a tentativa de priorizar um determinado marco teórico para compreensão desse vínculo. Neste último sentido, o que parece ser passível de problematização é a opção por desenvolver uma teoria social de amplo alcance a partir de categorias primariamente voltadas para uma análise da subjetividade. Com efeito, assumir a interdependência entre sujeito e sociedade não conduz, prima facie, a assumir a psicanálise como âmbito privilegiado para compreensão dessa relação. O questionamento, portanto, é não só se compreendemos o sujeito como indissociável de seus laços sociais, mas se, com esta premissa, nos é permitido utilizar categorias da psicanálise no âmbito de uma análise social.

No que concerne ao âmbito da filosofia, este vínculo estreito entre sujeito e sociedade é encontrado emblematicamente na tradição da assim chamada teoria crítica. E é significativo que, neste marco teórico, a psicanálise, em particular na sua formulação original a partir da teoria freudiana, assuma um papel crucial. Não seria exagero afirmar que, dentre as tradições filosóficas e sociológicas, é na teoria crítica em que a psicanálise se mostrou mais produtiva. Já na assim chamada primeira geração, nos autores ligados ao que ficou conhecido por Escola de Frankfurt, encontramos a influência marcante de Freud em autores como Adorno, Horkheimer, Herbert Marcuse e Erich Fromm. Uma das motivações recorrentes deste marco teórico é que, diferentemente de uma teoria tradicional, uma teoria crítica não mais possuiria o privilégio de se sustentar independente de outros tipos de discurso, passando a desprender-se de um eventual hermetismo filosófico. A passagem dessa pretensão teórica para aquilo que viria a se chamar de pensamento pósmetafísico é caracterizada por uma necessidade de abertura ao diálogo com demais ciências particulares. Com isso, a possibilidade de uma análise social, ainda que a partir de um marco filosófico, passa a ser indissociável do diálogo com contribuições como as da psicanálise ou da sociologia. É desse modo que a filosofia deveria deixar de possuir um estatuto com pretensões absolutas, para se tornar, antes, o que Habermas chamou de "guardadora de lugar" (Platæhalter) $^{2}$ : Ela permanece com estatuto autônomo, mas o diálogo com

2 Cf. HABERMAS, 1989. 
outras ciências particulares balizaria os seus respectivos domínios discursivos. A filosofia passa, então, por uma espécie de autocrítica, em que coloca em questão não só categorias específicas, mas os seus próprios pressupostos e pretensões teóricas.

No caso de uma teoria crítica da sociedade, a tensão que se tenta solucionar é entre uma teoria normativa e o seu potencial descritivo. Uma análise social deveria possuir uma chave interpretativa que não resvale em uma simples descrição neutra, abrindo espaço para uma leitura crítica da sociedade e de possíveis causas de déficits sociais. Sem essa concepção, correr-se-ia o risco de incorrer ou em uma teoria normativa demasiadamente abstrata, desacoplada da realidade, ou em uma teoria descritiva que não ofereça chave interpretativa e de crítica social. Através dessa proposta de revisão de seus pressupostos, a filosofia passa a ser vista como nexo entre diagnóstico de época e crítica social, cujo vínculo é encontrado na pluralidade de autores associados a esta tradição, passando por Adorno, Habermas, e tendo como principal expoente nas últimas décadas o filósofo alemão Axel Honneth.

Tomando como fio condutor a apropriação da psicanálise no contexto da teoria crítica, pretendo apresentar, no que se segue, ambivalências na relação entre conceitos psicanalíticos e teoria social. Inicialmente, tento mostrar como Adorno, ao tempo em que encontra em Freud as vantagens de uma perspectiva de descentramento do sujeito, também desenvolve a crítica a um possível inflacionamento de categorias psicanalíticas no âmbito da sociologia (1). Tendo em vista essa interpretação, discuto em que medida o vínculo entre categorias psicanalíticas e sociais pode permanecer produtivo, considerando o problema do estatuto epistemológico da psicanálise (2). Em um terceiro passo, apresento de forma sucinta a recente interlocução com a psicanálise proposta por Axel Honneth, sugerindo que conceitos como reconhecimento e patologia social apontam para um sentido produtivo de limites de uma teoria social (3). Concluo minha exposição sugerindo uma distinção entre três sentidos de sofrimento e terapia, cuja tipologia exemplifica de maneira paradigmática uma delimitação recíproca entre psicanálise e teoria social (4).

\section{Descentramento do sujeito e estatuto sociológico: Adorno e o problema do alcance teórico da psicanálise}

Se, durante as últimas décadas, a relação entre teorias psicológicas, em especial a psicanálise, e teoria social não cause surpresa, grande parte do desenvolvimento dessa interlocução teórica deveu-se aos esforços do círculo de intelectuais que passaria a ser conhecida por Escola de Frankfurt. Ainda que essa tentativa de relação possa ter sido controversa e alvo de críticas diversas, 
ela se desenvolveu como influente modelo teórico, passando a tomar parte no vocabulário comum das teorias sociais, em particular em tradições influenciadas por Marx. Como observa, com razão, Martin Jay: "Hoje, é difícil avaliar a audácia dos primeiros teóricos que propuseram o casamento antinatural de Freud e Marx. (...) Uma geração atrás, o absurdo dessa ideia raramente era questionado em qualquer lado do Atlântico" (2008, p. 133)

Ao longo dos trabalhos ligados ao Instituto de Pesquisas Sociais, berço da Escola de Frankfurt, a influência de Freud passou a ser tão decisiva que a discussão inicial sobre os pressupostos da teoria freudiana e de seu vínculo com uma análise social deu lugar ao uso frequente de termos psicanalíticos nos diversos estudos dos autores frankfurtianos, inclusive nas pesquisas empíricas desenvolvidas pelo Instituto. No seu contexto inicial, a recepção da psicanálise caracterizou-se marcadamente por uma delimitação diante das propostas do que Adorno viria a chamar de revisionistas ${ }^{3}$ - como Erich Fromm, Erick Erikson e Karen Horney -, que passaram a adotar com reservas o freudismo, principalmente por considerarem-no excessivamente dependente de um contexto marcado por uma cultura patriarcal e moralista. Ao invés de discutir em detalhes essa extensa querela - o que exigiria um estudo mais amplo -, gostaria de destacar dois aspectos que me parecem preponderantes na recepção da psicanálise neste contexto: se, por um lado, a recepção de categorias psicanalíticas contribuíra para o questionamento de uma noção de subjetividade estritamente racional e autocentrada, tal apropriação pelos teóricos ligados à Escola de Frankfurt sempre foi acompanhada, por outro lado, de uma ponderação crítica da teoria freudiana justamente por impasses na sua relação com uma teoria social. Como veremos, tal relação ambígua pode, na verdade, apresentar aspectos para se pensar uma delimitação produtiva entre psicanálise e teoria social.

Entre o amplo círculo de teóricos da Escola de Frankfurt, a principal tendência interpretativa deu-se na esteira dos trabalhos de Erich Fromm. Ao levar a cabo uma articulação entre teoria social e freudismo, Fromm vê na análise do inconsciente uma das principais contribuições de Freud, encontrando ali indícios de um limite de racionalidade que melhor descreveriam a subjetividade e suas ações dentro de um processo histórico mais amplo. Na tentativa de oferecer uma explicação mais sólida a aspectos da teoria marxista a partir da recepção de categorias psicanalíticas, Fromm propõe um leque variado de questões relacionadas a processos históricos e movimentos sociais, que vai da crítica ao sentido homogêneo de massa

${ }^{3}$ ADORNO, 2015a, 2015b. 
(enquanto ela seria composta por diferentes variantes psíquicas) até a proposta de uma tipologia do caráter apoiada na teoria freudiana da libido ${ }^{4}$.

A partir da influência de Fromm, também Horkheimer, em seu artigo História e psicologia, defende a urgência de uma complemento psicológico para a teoria marxista. Aqui, Horkheimer ainda está voltado para o sentido de uma psicologia individual - mesmo que não menosprezasse a influência de fatores sociais na constituição do sujeito. Contudo, diferentemente de Fromm, Horkheimer não via maiores problemas em um possível contextualismo da teoria freudiana enquanto enraizada numa situação histórica concreta - no caso, com uma certa conotação burguesa da cultura vienense da época. Pelo contrário, ele enxergava nisso uma postura que interpreta conceitos como pulsão de morte menos em conformidade com um biologismo com pretensões universais e mais como diagnóstico de impulsos destrutivos do sujeito moderno. Horkheimer permanece então mais próximo a Freud, acusando os revisionistas de tentar psicologizar a sociedade e a cultura. A sua crítica, como retomaremos mais adiante, dirigia-se fundamentalmente à tendência de um reducionismo recíproco entre sociologia e psicologia.

Mas é com Adorno que vemos uma guinada sociológica na constatação de que diversos sintomas antes descritos como fundamentalmente psíquicos possuiriam um nexo causal muito mais estreito com contextos sociais específicos ${ }^{5}$. Também em contraposição aos revisionistas, Adorno alerta para o risco de reduzirmos sintomas de uma época a categorias psicanalíticas, o que poderia impedir uma compreensão mais extensa de problemas de ordem social e política. Contrário a uma mera sociologização de conceitos psicanalíticos, Adorno chega a sugerir que "não há nenhuma neurose política", enfatizando uma dimensão socialmente mediada em passagens onde propõe que "a divergência entre indivíduo e sociedade possui uma origem essencialmente social, é perpetuada socialmente, e suas manifestações devem ser explicadas sobretudo socialmente" (2015a, p.81). É também nesse sentido que Adorno escreve que "o psicologismo em todas as suas formas, que toma o indivíduo como ponto de partida incondicional, é ideologia", na medida em que "ele enfeitiça a forma individualista da socialização como uma

${ }_{4}^{4} \mathrm{FROMM}, 1932$. Tais ideias seriam reformuladas em escritos posteriores, como 0 medo à liberdade $\mathrm{e}$ Análise do homem, em que Fromm passa a adotar o conceito de "caráter social", que consideraria sua "contribuição mais importante (...) para o campo da psicologia social" (Carta de Fromm para Martin Jay, descrita em Jay 2008, p.147). Para Fromm, "o caráter social abarca apenas uma seleção de traços, 0 núcleo essencial da estrutura de caráter da maioria dos membros de um grupo, desenvolvido como resultado das experiências básicas e do estilo de vida comuns a esse grupo". (FROMM, 1986, p. 39, itálico no original).

${ }^{5}$ Exemplo disso é o repercutido estudo sobre a personalidade autoritária (ADORNO et alii 1950).

${ }^{6}$ ADORNO 2015c, p.196. 
determinação extrassocial, natural, do indivíduo" (2015a, p.89). Tal proposta correria o risco de levar a uma dicotomia entre "uma sociologia sem sociedade" e uma psicologia que "percebe o interesse do sujeito, mas igualmente de forma isolada, 'abstrata" (2015a, p.91). Daí o filósofo concluir que "quanto mais estritamente o âmbito psicológico é pensado como um campo de forças fechado em si e autárquico, tanto mais completamente a subjetividade é dessubjetivada” (2015a, p.98).

Contra o que Adorno chama de "historicismo de fachada" dos revisionistas, impõe-se uma predominância de uma inserção social. É a ideia que ele encontra em Hartmann de que uma dada estrutura social não exprime, mas "escolhe" tendências sociológicas específicas. É também nesse sentido que, escreve Adorno,

a justificada suspeita de Parsons, de que os psicanalistas seriam incapazes de
empregar por si mesmos os conceitos analíticos de forma adequada aos
problemas sociais, vale não apenas para a tendência universal de especialistas em
estender seus conceitos parciais a uma totalidade que deles se afasta, mas
também para a impossibilidade de explicar de um ponto de vista psicológico o
que absolutamente não deriva da vida psíquica de seres humanos individuais
(2015a, p.82).

O resultado disso é que "ambas as disciplinas percebem sua própria insuficiência, mas não são capazes de se corrigir. Seu inevitável dualismo não pode se sustentar puramente" (2015a, p.91). E conclui:

Enquanto as leis sociais não podem ser "extrapoladas" de resultados de pesquisas psicológicas, no polo oposto o indivíduo não é simplesmente indivíduo e substrato da psicologia, mas sempre e ao mesmo tempo - na medida em que de algum modo se comporta racionalmente - portador das determinações sociais que o marcam (2015a, p.81).

Contudo, ao tempo em que Adorno alerta para o risco de uma "dessocialização" do sujeito, tal postura não significa advogar uma completa separação entre sociologia e psicologia, mas apenas uma delimitação de seu escopo:

Quem separa sociologia e psicologia rigidamente uma da outra elimina interesses
essenciais de ambas as disciplinas: o interesse da sociologia por sua relação
retroativa aos seres humanos vivos, por mais mediada que esta seja; o da
psicologia pelo momento social de suas categorias monadológicas (2015a,
p.130).

A questão central, portanto, seria como conceber uma relação produtiva entre ambas as disciplinas, uma vez que "existe ou existiu um domínio pátrio psicanalítico com evidência específica; quanto mais a psicanálise se distancia dele, tanto mais suas teses são ameaçadas pelas alternativas da superficialidade ou do sistema delirante" (2015a, p. 125). 
A partir dessa interpretação mais cautelosa da relação entre psicanálise e teoria social, Adorno se alinha à interpretação da própria psicanálise como sintoma de um tempo $\mathrm{po}^{7}$. Ou seja, por trás da aparência de uma afirmação da individualidade, a psicanálise pode se mostrar como mais um instrumento de adaptação social - ainda que seus antagonismos exigissem antes uma postura de ruptura do que adequação. Por isso, escreve Adorno, "o antagonismo social reproduz-se no objetivo da análise, que não mais sabe, nem pode saber, para onde quer conduzir o paciente, se para a felicidade da liberdade ou para a felicidade na não-liberdade"8.

Entretanto, Adorno encontra na teoria freudiana a inspiração para uma concepção de descentramento do sujeito, justamente na tentativa de romper com o mito de uma unidade da personalidade. Para o frankfurtiano, permanece inspiradora, sobretudo, a desconstrução da crença na racionalidade como instância preponderante do sujeito. Nesse sentido, Adorno compartilha bem mais um certo pessimismo de Freud do que o otimismo de Fromm e dos revisionistas: no lugar de conceitos como esperança e reconciliação, Adorno passa a enfatizar a contradição e antinomia de inspiração freudiana, sugerindo que o eu encontra seus limites não somente em um realidade externa, mas em uma tensão interna. Contra as ilusões harmonizadoras dos revisionistas, Freud teria constatado contradições intransponíveis da subjetividade, apontando para um significado terapêutico distante de uma "cura" total e mais próximo daquilo que Freud irá entender como passar da miséria neurótica à infelicidade banal (ou ainda, num outro registro, de uma amarração do sintoma - o que Lacan chamou de sinthome $e^{9}$. O pessimismo de Freud não seria, no entanto, sintoma de um desespero normativo, mas de um realismo consequente. Pelo contrário, justamente por impasses inerentes à subjetividade é que a solução freudiana teria se voltado para aquilo que pode ser tratado pela clínica psicanalítica. Amar e trabalhar - criticados como indício do conformismo burguês de Freud - seria, na verdade, aquilo que restaria à saúde psíquica, um modo de lidar com o real que permanece, em si mesmo, irresoluto.

Adorno, por sua vez, insiste em uma tensão negativa entre conteúdo psíquico e mediação social, afirmando que "o conceito do eu é dialético,

${ }^{7}$ Como observa Christian Dunker, esse problema levantado por Adorno é central para outras leituras subsequentes do freudismo: "Admitir que a psicanálise tornou-se parte do problema que pretendia resolver, que sua inevitável culturalização exige um trabalho de crítica interna permanente, não indiferente às demandas conformistas inerentes à sua prática e à promessa terapêutica, foi também um sentido de muitas leituras entre as quais Adorno se inscreve como pioneiro. De Reich a Lacan, de Ferenczi ao casal Torock, reencontramos os mesmos pontos levantados pela crítica seminal de Adorno" (DUNKER, 2015, p. 23).

${ }^{8}$ Cf. ADORNO, 2015a, p.122-3.

${ }^{9}$ LACAN, 2005. 
psíquico e não psíquico, um fragmento da libido e o representante do mundo", sugerindo que "Freud não tratou dessa dialética" (2015a, p.107). A partir da crítica a aporias de uma identidade absoluta, a proposta adorniana é a de que "a identidade entre sociedade e indivíduo na forma em que ela se encaminha é o totalmente negativo: assim ela é experimentada pelo indivíduo através de dor física e sofrimento psíquico" (2015a, p.134) ${ }^{10}$. A conclusão da crítica do frankfurtiano a Freud pode ser resumida da seguinte maneira:

Não se deve reprovar Freud de ter desprezado o concretamente social, mas sim por ter se contentado de forma fácil demais com a origem social daquela abstração, com a fixidez do inconsciente, apreendida por ele com o caráter incorruptível do pesquisador da natureza. O empobrecimento através da interminável tradição do negativo fora hipostasiada por ele como uma determinação antropológica (2015a, p.96).

Vale lembrar brevemente que tais pressupostos da teoria freudiana encontram um eco próprio na articulação de uma teoria social ampliada em Herbert Marcuse. Como Adorno, Marcuse defende a ideia freudiana de um indivíduo cindido, em que o significado de uma individualidade autêntica seria sempre nebuloso. Exemplo disso é o modo como Marcuse, diferentemente de Fromm, entende o conceito de felicidade: enquanto Fromm passa a adotar a centralidade desse conceito na prática clínica, Marcuse alerta para o sentido travestido de ideologia que a concepção de felicidade pode esconder, cujo significado poderia, em última análise, revelar-se opressor. Como escreve o filósofo, "em uma sociedade repressora, a felicidade individual e o desenvolvimento produtivo estão em contradição com a sociedade; quando são definidos como valores a ser realizados nessa sociedade, eles mesmos se tornam repressores" (MARCUSE, 1981, p.223).

Desse modo, Marcuse propõe uma interpretação mais ponderada das pulsões destrutivas. Como saída para um caráter reificador de uma sociedade baseada no "princípio do desempenho", o Marcuse de Eros e Civilização vê, no que chamou de "princípio do Nirvana" e no conceito de "perversão polimorfa", uma possível via de libertação do indivíduo. Resta saber se seria viável conceber uma compatibilização entre satisfação sexual e civilização aspecto destacado na crítica que receberia de Erich Fromm ${ }^{11}$ - sem mencionar

${ }^{10}$ Em uma outra passagem, Adorno afirma que "esse recalque da impotência aponta não apenas para a desproporção entre o indivíduo e sua força dentro da totalidade, mas, mais ainda, para a ferida de seu narcisismo e para a angústia de perceber que a falsa superpotência, perante a qual todos tem motivos para baixar a cabeça, se compõe propriamente deles mesmos" (2015a, p.112).

11 FROMM, 1955. Também sobre essa controversa, ver a instrutiva reconstrução de Martin Jay (2008, cap.3). Sobre outros aspectos importantes na apropriação da psicanálise no contexto da teoria crítica, cf. MARIN, 2008. 
o caráter utópico do presente. A negação do real, encontrando apenas na afirmação de uma sexualidade primária a sua salvação, poderia revelar um certo niilismo desesperançoso. Uma posição que, em última análise, desvela uma linha tênue entre utopia e pessimismo.

Diferentemente de Fromm, tanto Adorno como Marcuse tinham em vista, sobretudo, salvar um potencial da teoria freudiana, sem mascarar antagonismos fundamentais. No entanto, a contribuição a uma crítica consequente da racionalidade levada a cabo a partir da apropriação de Freud vinculou-se a uma reconsideração de certos pressupostos da psicanálise, em particular na sua relação com um diagnóstico social. No caso de Fromm, vemos um distanciamento mais contundente do freudismo ortodoxo, como na crítica à teoria da libido e à metapsicologia freudiana e a conceitos centrais como o complexo de Édipo e à pulsão de vida e pulsão de morte ${ }^{12}$. O exemplo da crítica de Fromm - mas também, em menor medida, dos demais frankfurtianos - parece conduzir a um revisionismo tão incisivo que não surpreenderia o questionamento sobre o que resta do freudismo em sua proposta teórica. O que se deixa entrever é um caso emblemático de encontrar, nas descobertas clínicas de Freud, uma de suas contribuições mais significativas, ainda que se questione certos aspectos de suas reflexões no âmbito da metapsicologia. É este aspecto em particular, naquilo que podemos chamar de problema do estatuto epistemológico da psicanálise, que eu gostaria de discutir um pouco mais detidamente no tópico seguinte.

\section{Divisão de trabalho: sobre a delimitação recíproca entre psicanálise e teoria social}

Desde as primeiras contribuições na esteira da teoria crítica, como vimos, encontramos uma problematização mais ampla em torno do alcance teórico da psicanálise. Tais propostas consistem justamente em não tomar como dados certos pressupostos do freudismo. Segundo a ideia de uma crítica interna, o questionamento de alguns desses conceitos não deve ser entendido como interpretação equivocada da psicanálise, mas pode evidenciar algum aspecto restritivo da proposta teórica - o que, de resto, revela uma postura de honestidade intelectual. Em resumo, trata-se de confrontar a psicanálise antes como "invenção" do que "descoberta"13.

\footnotetext{
12 Cf. FROMM, 1932.

${ }^{13}$ Certamente, invenção deve ser compreendida, aqui, em um sentido bastante específico, próprio do nexo entre teoria e "real", numa querela que remete ao cerne das distinções entre posições realistas e antirrealistas em epistemologia - o que exigiria uma reconstrução delongada sobre o estatuto científico das ciências humanas. Sem ser possivel analisar com 0 detalhamento necessário essas questões, 0
} 
Com efeito, as diversas abordagens psicológicas, assim como teorias sociológicas e mesmo filosóficas, possuem, em graus distintos, pretensões de "verdade" - entendidas fundamentalmente como tentativas de melhor descrever a realidade. Desde a célebre formulação nietzschiana de que "não há fatos, somente interpretações", o papel da teoria na descrição do real torna-se ainda mais obscuro. Não só da teoria, como também do real, são retiradas as pretensões de objetividade e verdade, restando para uma teoria descritiva um significado ambivalente. Suprindo-se os fatos, cabe à interpretação a tarefa de um discurso muitas vezes impregnado de ceticismo - quando não travestido de um cinismo sem reservas.

Ao questionarmos, contudo, certos pressupostos da teoria freudiana, estamos, pelo que parece, nos movendo no limite tênue entre psicanálise e psicologia lato sensu - ou seja, nas dificuldades teóricas de delimitação de uma abordagem específica sobre o sujeito. Em outras palavras: até que ponto propostas revisionistas ainda se mantém qua teoria psicanalítica? O próprio percurso da psicanálise mostrou-se não como um núcleo conceitual estático, senão dotado de uma constante dinamicidade de seus principais conceitos. Tal sentido valeu já na sua própria formulação original em Freud, bem como posteriormente nos seus seguidores, que, de um modo ou de outro, propuseram novos conceitos e formulações. Ora, quais os critérios que fazem com que entendamos que reformulações como as de Anna Freud, Jacques Lacan ou Melane Klein, só para citar alguns, permaneçam categorizadas como psicanálise, enquanto Erich Fromm, Karen Horney e Gustav Jung, não o seriam? Haveria um "núcleo duro" de conceitos que se estabelece como critério de delimitação da teoria psicanalítica?

Certamente, estamos também aqui no terreno ardiloso de incomensurabilidade de paradigmas, no qual se deve respeitar a especificidade epistemológica da psicanálise. Cabe lembrar que a posição freudiana diante dos critérios de cientificidade e as reservas com a filosofia é largamente associado ao seu contexto vienense onde dominava o positivismo lógico. Sem nos atermos a especulações, é possível que um outro contexto tenha legado ao freudismo outros conceitos. Mas uma teoria é fruto de seu tempo, ainda que possa ambicionar um alcance atemporal. Além disso, é importante distinguirmos aqui entre o estatuto epistemológico e o desdobramento prático dessas posições - lembrando que, em muitas delas, houve uma ruptura

meu interesse aqui é, antes, concentrar-me em um sentido mais restrito em torno do estatuto epistemológico da psicanálise. 
explícita com o freudismo, além das várias divergências e querelas de caráter institucional.

No entanto, um dos principais aspectos de caráter epistemológico da teoria psicanalítica parece ser, desde o próprio percurso revisionista já em Freud, que a formulação e a revisão de conceitos se dava a partir da observação clinica. Diante das críticas que lhe são imputadas, a psicanálise tem sempre um trunfo a seu favor: a eficácia da clínica. Certamente, o sentido de "eficaz" aqui é bastante particular, pois ele já envolve uma compreensão específica, uma vez que aquilo que é entendido como objetivo da clínica já é distinto do que outras abordagens tomariam por resultado "eficaz". Em todo caso, é a clínica que parece ser um dos âmbitos privilegiados da teoria psicanalítica, tanto na construção de seus conceitos quanto na sua aplicação. É nesse sentido que seria apropriado distinguirmos entre efeitos clínicos do tratamento psicanalítico e os impactos da psicanálise na cultura, como veremos mais adiante.

Mas a teoria psicanalítica vê-se confrontada, ainda, com uma outra objeção, que pode ser descrita como um pêndulo entre o universal e particular. Trata-se da dificuldade de conciliação entre uma teoria pretensamente universal e a particularidade da clínica e das biografias individuais. Pois, ao se agarrar a uma particularidade intransponível, a psicanálise corre o risco de recair em contradição performativa: ela espera falar de categorias universais que, se levada a sério o caráter radicalmente particular do indivíduo, nunca poderiam ser aplicadas.

A psicanálise vê-se, então, confrontada tanto por um excesso de particularismo, em que categorias teóricas se mostrariam impotentes, como por uma universalidade colonizadora, em que a teoria extrapolaria o seu âmbito específico. Enquanto, no primeiro caso, temos a ambiguidade em torno da clínica, mencionado anteriormente, o segundo caso refere-se propriamente às ambiguidades da psicanálise e da teoria social. Tal inflacionamento das pretensões de alcance da psicanálise agudiza-se com o seu desdobramento, a ponto do Freud tardio afirmar que "também a sociologia, que trata do comportamento do ser humano em sociedade, não pode ser nada mais do que psicologia aplicada" ${ }^{14}$. Tal sentença pode conter uma certa verdade, à medida que uma análise social estaria voltada para relações intersubjetivas, ainda que com um emaranhamento bem mais difuso do que simplesmente ampliar uma análise do sujeito para um conjunto de indivíduos. Concluir da premissa de que a sociedade é uma teia de relações intersubjetivas (e que, portanto, a sociologia é psicologia aplicada) pode perder de vista a

14 FREUD, 1999, p.194. 
delimitação recíproca entre os escopos distintos dos dois campos de conhecimento, ou ainda, levar à corrosão do estatuto específico das ciências sociais. Não por acaso, como se sabe, Lacan apresentava uma postura de um certo menosprezo à sociologia.

Contudo, como vimos a partir de Adorno, essa promessa tende a ser improdutiva, à medida que a aplicação irrestrita de categorias psíquicas se revelará obsoleta para avaliar uma sociedade que, de fato, é composta por sujeitos, mas que não se reduz nem a um sistema isolado, tampouco a uma análise consequente de cada conjunto que compõe a sociedade (o todo, como escreve Aristóteles em sua Metafisica, é maior do que a soma das partes). Para usar uma imagem da biologia, seria a anomalia de uma fagocitose que, na verdade, esconde uma relação parasitária. O sentido inverso é de uma certa precedência da sociologia diante das categorias da psicanálise. É nesse sentido que Adorno afirma:

Em vista da presente impotência do indivíduo - de todos os indivíduos -, a
sociedade, bem como a sociologia e a economia que dela se ocupam, tem a
primazia na explicação de processos e tendências sociais. Mesmo quando o
indivíduo age individualmente - embora no sentido de Max Weber aja
socialmente -, o órgão de tal agir, a ratio, é essencialmente uma instância social,
não psicológica (2015, p.128).

À primeira vista, tem-se a impressão que a posição adorniana pode novamente levar a um reducionismo, agora, inversamente, da psicologia à sociologia. O conflito entre as duas alternativas teóricas não parece ser muito diferente da oposição clássica entre a ênfase na influência do social sobre o individual ou a opção pelo individualismo metodológico - tendências que marcam grande parte da sociologia desde Weber. Uma das motivações implícitas da posição de Adorno é que interpretar momentos sociais como o papel de indivíduos em um grupo tende a fracassar. Processos socialmente disruptivos seriam mais complexos do que apenas um nexo causal de relações individuais. Apreender a história, diria Hegel, requer bem mais do que a narrativa de ações particulares isoladas. É como se movimentos sociais pudessem, por assim dizer, ser apreendidos autonomamente.

Certamente, a uma posição aparentemente dicotômica encontra-se um leque de variantes teóricas, e, mais precisamente, abordagens distintas no âmbito da psicologia social. Contudo, na interpretação que proponho em torno da relação entre psicanálise e teoria social, parece ser mais promissor o sentido de complementariedade, ou seja, uma correlação entre as duas disciplinas tanto em uma demarcação mútua como em um aprendizado complementar. Ou seja, trata-se de um movimento em três etapas: após um primeiro momento de indistinção entre teoria do sujeito e teoria social, cabe 
uma etapa intermediária de delimitação recíproca para, por fim, chegarmos a um diálogo produtivo de interdependência entre os dois campos. Pois, tanto a psicanálise quanto a teoria social encontram seus limites dos quais uma ou outra não podem ultrapassar, com problemas específicos que não podem ser esgotados em um âmbito isoladamente. É este o sentido que tentei destacar na abordagem adorniana, que propõe que "a psicologia é relevante não apenas como meio de adaptação, mas também onde a socialização encontra seus limites no sujeito" (2015a, p.135).

Quem, tal como Freud, concebesse a sociologia como psicologia aplicada, cairia, apesar de toda a intenção esclarecedora, na ideologia. [...] Tampouco se deve sociologizar a psicanálise. [...] Os conhecimentos psicológicos e sociais são tão mais decisivos e podem ser tão mais significativos reciprocamente quanto menos um se apoia imediatamente no outro (ADORNO, 2015a, p.131).

Um dos aspectos que, ao meu ver, melhor expressam uma interdependência e os limites do escopo da psicanálise e da teoria social consiste na distinção entre sentidos de sofrimento e significado terapêutico, característicos da retomada da psicanálise no projeto teórico de Axel Honneth. Trata-se, como veremos a seguir, não mais da questão em torno do estatuto epistemológico da psicanálise, como marcante entre as reflexões da primeira geração da teoria crítica, mas de uma ressignificação de conceitos como patologia e terapia a partir de condições socialmente mediadas. É nesse sentido que, como tentarei mostrar, podemos novamente encontrar na proposta honnethiana um sentido produtivo para a delimitação entre psicanálise e teoria social.

\section{Reconhecimento e patologia social: Axel Honneth e o retorno da psicanálise na teoria crítica}

Após o contexto inicial da recepção da psicanálise na teoria crítica, a interdependência entre teorias da subjetividade e teoria social permanece como fio condutor das propostas subsequentes, mas a psicanálise perde o seu espaço privilegiado como marco conceitual. Com efeito, Jürgen Habermas, principal expoente da assim chamada segunda geração da teoria crítica, distancia-se do recurso à psicanálise recorrente entre os teóricos da Escola de Frankfurt, passando a aproximar-se da psicologia social de viés pragmatista de G. H. Mead e da psicologia do desenvolvimento de Piaget e Kohlberg. Se em Conhecimento e interesse ainda vemos Habermas voltando sua atenção para o papel de Freud em uma análise crítica da sociedade ${ }^{15}$, com sua posterior opção em recorrer a outras correntes da psicologia moral e do desenvolvimento, é

15 HABERMAS, 1982, Cap.10. 
deixado de lado o papel fundamental que a psicanálise desempenhava no projeto original da teoria crítica.

É somente com Axel Honneth que uma chave de interpretação de base psicanalítica volta a ocupar lugar de destaque. No seu principal livro, intitulado Luta por reconbecimento, o autor desenvolve o programa de uma teoria social a partir do vínculo entre constituição da identidade individual e relações intersubjetivas de reconhecimento, em que a articulação de experiências individuais dependeria do que Honneth desenvolveu nos padrões de uma "gramática moral"16. Partindo de uma releitura de Hegel, a ideia básica é a de que o sujeito desenvolve suas capacidades e uma relação positiva consigo próprio a partir de relações de reconhecimento socialmente mediadas, seja ela dos padrões do amor (nas relações afetivas no âmbito da família), dos direitos (assegurados juridicamente) e da solidariedade (no âmbito do mercado e do trabalho). $\mathrm{O}$ autor sugere que, quando essas condições sociais não são preenchidas, o sujeito é atravessado por experiências de menosprezo e desrespeito, tendendo a reagir através de articulações de uma "luta por reconhecimento". Com isso, as relações de reconhecimento são entendidas no sentido de um crescente grau de conscientização da dignidade individual, discutida não mais nos pressupostos de uma teoria atomista da autonomia, senão a partir de estruturas de reconhecimento recíproco.

É nesse sentido que Honneth, a partir da assim chamada teoria hegeliana da eticidade, encontra nas esferas das relações sociais (família, sociedade civil e Estado) modos específicos de reconhecimento social. A proposta honnethiana em Luta por reconhecimento pode ser assim resumida:

O nexo existente entre a experiência de reconhecimento e a relação consigo próprio resulta da estrutura intersubjetiva da identidade pessoal: os indivíduos se constituem como pessoas unicamente porque, da perspectiva dos outros que assentem ou encorajam, aprendem a se referir a si mesmos como seres a que cabem determinadas propriedades e capacidades. A extensão dessas propriedades e, por conseguinte, o grau de autorrealização positiva crescem com cada nova forma de reconhecimento, a qual o indivíduo pode referir a si mesmo como sujeito: desse modo, está inscrita na experiência do amor a possibilidade da autoconfiança, na experiência do reconhecimento jurídico, a do autorrespeito e, por fim, na experiência da solidariedade, a da autoestima (HONNETH, 2003, p. 272).

${ }^{16} \mathrm{Cf}$. HONNETH, 2003. Mais recentemente, esse projeto programático é desenvolvido em HONNETH, 2011. Sobre o desenvolvimento dessa perspectiva nos trabalhos mais recentes de Honneth, cf. CAMPELLO, 2014. 
Com esta ampliação de uma análise social a partir de uma tipologia de experiências de reconhecimento intersubjetivo, a teoria de Honneth abre espaço para aquilo que entendo como uma "virada afetiva" na teoria crítica: no marco de uma teoria do reconhecimento, o modelo honnethiano indica uma flexibilização de uma concepção de racionalidade forte a partir da ênfase em experiências emotivas negativas como sofrimento, menosprezo ou desrespeito, de onde Honneth extrai um potencial normativo imanente para, inversamente, propor experiências positivas de constituição do sujeito.

Meu propósito, aqui, não é tanto o de apresentar pormenores da teoria honnethiana, mas fundamentalmente o de discutir em que medida ela contribui para a interpretação que proponho em torno da relação entre psicanálise e teoria social. Em Luta por reconbecimento, Honneth recorre à psicanálise ao discutir uma possível inflexão empírica da tipologia do reconhecimento concernente às relações afetivas primárias, mais especificamente na família. É na teoria de relações de objetos do psicanalista inglês Donald Winnicott que o autor encontra as bases para tal proposta de fundamentar como as relações afetivas de reconhecimento são fundamentais para a articulação da autoestima na criança, vista como pré-condição para as ulteriores relações de reconhecimento. A preferência de Honneth por Winnicott se dá não somente devido à ênfase nos pressupostos intersubjetivos da constituição do sujeito, mas, sobretudo, por encontrar no psicanalista inglês uma abordagem psicanalítica empiricamente sustentada - como nos seus estudos em torno do desenvolvimento da subjetividade infantil - que poderia servir como fundamentação para o marco teórico discutido a partir de Hegel ${ }^{17}$. A ideia básica explorada na teoria winnicottiana é a de que um bebê desenvolve a sua subjetividade a partir de relações de afetos com sua pessoa de relação (Bezusperson), que exprimem, em um primeiro momento, uma relação de dependência absoluta e que, paulatinamente, proporcionam uma posição de independência do sujeito. É através do reconhecimento afetivo intersubjetivamente mediado que a criança paulatinamente desenvolveria uma relação positiva consigo mesmo.

Ao menos inicialmente, Honneth recorre à psicanálise para a discussão específica sobre a constituição fundamental do amor nas relações primárias da criança, sugerindo que o desenvolvimento de sua subjetividade dependeria de uma crescente afirmação do seu sentimento de autoestima. Essa

${ }^{17}$ Essa preferência honnethiana por Winnicott é alvo de controvérsia na literatura. Por exemplo, Amy Allen (2015) propõe que uma interlocução mais promissora poderia ser desenvolvida a partir de Melanie Klein, sugerindo que na abordagem kleiniana haveria uma maior ênfase na dimensão do conflito que melhor embasaria a proposta de Honneth. Em um outro registro, Vladimir Safatle (2015) propõe uma interpretação crítica de Honneth a partir de uma releitura de Freud e Lacan. 
discussão inicial e, em certo sentido ainda esquemática, iria se desenvolver sob outros parâmetros no decorrer dos escritos posteriores de Honneth. O autor irá propor a revisão do significado emblemático do conceito de amor com um sentido normativo fundamentalmente distinto das relações de solidariedade e do direito concernente às esferas da sociedade civil e do Estado ${ }^{18}$. Já mais recentemente, Honneth deixa em segundo plano as fortes premissas antropológicas presentes em Luta por Reconbecimento e retorna a Hegel em uma ambiciosa reformulação de uma teoria da justiça, em que os pressupostos do reconhecimento passam a ser relidos a partir de parâmetros de uma teoria das instituições ${ }^{19}$. Nessa nova aposta teórica, o reconhecimento passa a cumprir o papel de um horizonte normativo, dando lugar ao conceito de liberdade social: trata-se de reconstruir (no sentido específico do que Honneth entende por "reconstrução normativa") em que medida as instituições incorporam os pressupostos sociais de efetivação da liberdade ${ }^{20}$.

Um dos principais objetivos de Honneth nesse recente projeto é o de articular critérios para um diagnóstico de época a partir do conceito de patologias sociais. Em uma apropriação que remete a Rousseau e Durkheim, patologias sociais são entendidas como déficits nas suas diversas esferas, em particular ao que Honneth entende como patologias da liberdade negativa e da liberdade reflexiva ${ }^{21}$. O principal sentido encontrado ao longo da proposta honnethiana refere-se à tentativa de, inversamente, evidenciar parâmetros socialmente mediados de um desenvolvimento "saudável" do sujeito, como veremos mais adiante.

Contudo, o recurso de Honneth ao vocabulário de patologia e significado terapêutico não é explicitamente vinculado a categorias psicanalíticas. Se, por um lado, a menção à psicanálise em O Direito da Liberdade é esporádica, o que se percebe ao longo dos seus escritos é que ela teria o potencial, no contexto de uma teoria crítica da sociedade, de fornecer categorias para uma melhor compreensão de problemas de subjetivação tanto

\footnotetext{
18 HONNETH/RÖSSLER, 2008.

19 HONNETH, 2011. Sobre isso, cf. CAMPELLO, 2014.

${ }^{20}$ Como escreve Honneth em um estudo preparatório sobre a Filosofia do Direito de Hegel: "Se a liberdade individual designa primeiramente e, sobretudo, o 'ser-consigo-mesmo-no-outro', então a justiça das sociedades modernas se mede pelo grau de sua capacidade de assegurar a todos os seus membros, em igual medida, as condições dessa experiência comunicativa e, portanto, de possibilitar a cada indivíduo a participação nas relações da interação não-desfigurada". (HONNETH, 2007a, p. 78-79). E mais adiante: "Se a realização da liberdade individual está ligada à condição da interação, uma vez que os sujeitos somente podem se experienciar como livres em suas limitações em face de um outro ser humano, então deve valer para toda a esfera da eticidade o fato de ter de residir nas práticas de interação intersubjetiva". (HONNETH, 2007a, p.107)

${ }^{21}$ HONNETH, 2011, p.157s., p.206s.
} 
em um nível ontogenético primário - como nas relações afetivas na família como também em uma dimensão mais ampla de modos de constituição social. Tal sentido mais extenso de patologias sociais refere-se não apenas ao âmbito que estamos discutindo das categorias da psicanálise e da cultura, mas também indicariam, em última análise, um sentido deficiente de modelos de racionalidade 22 . É a partir dessa ampliação que, em outros trabalhos, Honneth passa a recorrer, por um lado, a conceitos de Freud para tentar explicar uma dimensão mais abrangente de análise social e suas patologias ${ }^{23}$ e, por outro, a um redimensionamento da categoria do reconhecimento em níveis ontológicos e epistemológicos ${ }^{24}$. Nesses escritos, Honneth destaca o papel constitutivo de experiências afetivas pré-discursivas, sugerindo uma ênfase na práxis de reconhecimento como experiência cognitiva primária ${ }^{25}$, onde é discutida a precedência de uma experiência prático-afetiva com o mundo diante de uma teórico-cognitiva. Desse modo, encontramos ao longo dos textos de Honneth sentidos implícitos de "patologia" associados a outros conceitos como reificação, invisibilidade e autorrealização organizada ${ }^{26}$.

Como se vê, também na proposta de Honneth há uma certa tensão no recurso à psicanálise. Pois, se é mais propriamente indicada a referência a categorias psicanalíticas no âmbito da constituição primária da subjetividade, elas não são excluídas do escopo de um diagnóstico social. Em ambos os níveis interpretativos (ontogenético e de teoria social), contudo, percebe-se um entrecruzamento entre subjetividade e mediações sociais: Se, no âmbito da teoria social, é sugerida mais claramente a aplicação de categorias psicanalíticas na crítica da sociedade e suas patologias, também o recurso ao nível primário de constituição do sujeito revela uma preocupação com relações socialmente mediadas de reconhecimento, em que um conteúdo afetivo é visivelmente mais presente. A interlocução com a psicanálise não indicaria apenas que sua apropriação estaria circunscrita a uma teoria primária da subjetividade - como é mais recorrente no debate sobre a teoria honnethiana -, mas também que a discussão sobre relações afetivas primárias não se deixaria desvencilhar de uma análise social ampliada ${ }^{27}$.

\footnotetext{
22 HONNETH, 2014. Sobre o conceito de patologia social, cf. ainda NEUHOUSER, 2000.

23 HONNETH, 2010.

24 HONNETH, 2008.

25 HONNETH, 2005.

26 Cf. HONNETH, 2001; 2004; 2008.

${ }^{27}$ Esse aspecto refere-se ao próprio vínculo entre conteúdo afetivo e as demais esferas do projeto teórico de Honneth, ou seja, sobre uma maior precisão, por um lado, da interdependência entre conteúdo afetivo e relações mais amplas da sociedade civil, e, por outro, das garantias e limites da dimensão jurídica - o que, contudo, não cabe discutir em pormenores aqui (discuti esses aspectos em CAMPELLO, 2015). Interessa-me, sobretudo, entender em que medida a proposta honnethiana, no
} 
No entanto, se, por um lado, abre-se a perspectiva de ampliação de uma teoria social a partir da inclusão de conteúdos afetivos, o projeto honnethiano se desenvolve alicerçado em uma visão de subjetividade dependente de conceitos conclusivos (como "autorrealização") e em uma análise social a partir de conceitos ainda ambíguos, como é o caso de "reconstrução normativa"28 (que deixam ainda obscuro o significado de uma crítica das instituições) ou daquilo que Honneth em referência a Frederick Neuhouser consolidou com o vocabulário em torno de patologias sociais, sofrimento e "significado terapêutico da eticidade" ${ }^{29}$. Contudo, o projeto teórico de Honneth, ao meu ver, circunscreve-se àquilo que é possivel descrever no âmbito de uma teoria social, onde se estrutura, primeiramente, um nexo entre subjetividade e reconhecimento recíproco, e, mais recentemente, a incorporação dos conteúdos de realização da liberdade social pelas instituições ${ }^{30}$. O que se mostra, na verdade, é um propósito de autolimitação, ou seja, aquele sentido de autorrealização e terapia concernente ao propósito normativo de uma teoria social. Este aspecto é o que entendo como mais promissor para a nossa discussão dos limites de um diagnóstico social a partir de categorias psicanalíticas.

\section{Sofrimento(s) e terapia(s)}

Procurei mostrar que uma das principais contribuições teóricas de Axel Honneth pode ser encontrada no conceito de patologia social e no alcance que a psicanálise pode cumprir em um diagnóstico social. A ideia é a de que uma teoria social deve se referir a um âmbito específico, no qual podemos falar de significado terapêutico de estruturas sociais e do papel das instituições. Trata-se, portanto, daquilo que podemos entender como sofrimento social, ou dimensão social do sofrimento, e daquilo a que se referem estruturas sociais. Teoria social e psicanálise apresentam, nesse sentido, significados "terapêuticos" distintos: enquanto a primeira refere-se a um conjunto determinado de questões (justiça social, igualdade de oportunidades, garantias de direitos, etc..), uma outra dimensão do sujeito não se deixa reduzir ao alcance da teoria social, como no exemplo paradigmático da teoria psicanalítica.

marco da teoria crítica, pode contribuir para uma revisão em torno do papel da psicanálise para uma teoria social.

28 HONNETH, 2011.

${ }^{29} \mathrm{Cf}$. HONNETH, 2007 e NEUHOUSER, 2008.

${ }^{30}$ Abordei esse aspecto em CAMPELLO, 2014. 
Nesse sentido, gostaria de concluir distinguindo entre três tipos de sofrimento. A um primeiro refere-se o campo de uma teoria social, que consiste no que pode ser entendido como sofrimento social. A este aspecto refere-se mais propriamente uma teoria normativa: um quadro de dever-ser que poderia mitigar causas sociais do sofrimento psíquico. O segundo tipo deve-se justamente à contingência desse processo: é pelo fato de uma relação intersubjetiva não depender de um conteúdo previamente determinado que uma teoria social não pode satisfazer todos os critérios de uma subjetividade plenamente imune ao sofrimento e ao sintoma. A pretensão de uma teoria normativa, portanto, esbarra no próprio caráter contingente das relações sociais. Pois é devido à vulnerabilidade e à contingência que não se pode determinar normativamente todos os conteúdos das relações sociais. Um terceiro tipo de sofrimento seria derivado do próprio processo de subjetivação - como aquilo que Freud entende como castração ou o que Lacan denomina de alienação e separação ao Outro primordial. Há, portanto, um teor de sofrimento como transcendental no sentido kantiano, ou seja, como inerente à própria condição de possibilidade da subjetividade.

Ao primeiro tipo de sofrimento, ou, no sentido mais amplo, de patologia social, cabe uma análise criteriosa pertinente a uma teoria social. Dela depende um afastamento de casuísmos para interpretar o conteúdo "universal", que exprima um sintoma de um tempo e de uma sociedade, impregnados de historicidade, mas que resistem a uma mera consideração particular. É tarefa da filosofia, como já entendia Hegel, apreender o seu tempo em conceito. Cabe, portanto, a este modelo de teoria social resgatar o sentido de uma normatividade imanente e indissociável da crítica: o conteúdo normativo consiste não na pretensão de categorias formais ideais, mas em uma melhor explicitação da realidade social. O potencial normativo consiste, antes de tudo, na sua perspicácia interpretativa.

Mas é no caráter contingente da intersubjetividade que esbarra a pretensão normativa de uma teoria social. Honneth parte do seu projeto apontando para um limite em particular: o da fixação de teorias normativas em princípios, distanciando-se de uma análise crítica da sociedade ${ }^{31}$. Eu gostaria de insistir em um outro limite, resultado também da análise crítica da sociedade. Trata-se dos aspectos da subjetividade irredutíveis ao caráter intersubjetivo. É justamente esse limite, mencionado mais acima como processo de autocrítica da filosofia e como delimitação do escopo de uma teoria social, que parece ser

31 Honneth inicia O Direito da liberdade afirmando que "uma das maiores limitações que sofre a filosofia política contemporânea é a sua separação de uma análise social e, com isso, a fixação em puros princípios normativos" (2011, p. 14). 
igualmente promissor para compreender, inversamente, os limites da teoria psicanalítica. Tais limites, como já deve ter ficado claro, não se referem a um caráter deficiente da teoria, mas apenas a seu escopo. A divisão de trabalhos internos, como Weber já apontava, conduz, conforme mencionado, a um duplo movimento de autolimitação, mas também de uma necessária abertura e diálogo entre diferentes âmbitos. É nesse sentido que a interlocução entre psicanálise e teoria social, como já proposto na tradição da teoria crítica, revela não tanto a insuficiência de cada marco teórico, mas uma resposta promissora através de uma análise não-reducionista do enredamento entre sujeito e sociedade.

Tal visão, contudo, não deve ser confundida com resignação diante do formato das relações sociais. O limite da psicanálise não deve ser entendido como justificação de um contexto específico, mas apenas que não concerne à teoria psicanalítica a palavra final no diagnóstico e na terapia da sociedade. Uma desesperança diante de soluções conclusivas poderia ser tudo, menos legitimação das aporias entre sujeito e sociedade. Pois a abordagem freudiana parece indicar o sentido de "saudável" ao alcance da psicanálise, ou seja, daquilo que lhe compete no âmbito da subjetividade. Daí podermos afirmar que, ainda que a psicanálise possa oferecer ao sujeito a possibilidade de amar e trabalhar como sintomas de uma vida "normal", as suas formas e expectativas dependem de rupturas que somente podem ser confrontadas a partir de uma perspectiva ampliada daquilo que envolve o "social".

A questão que se impõe é se há um limite do alcance de uma teoria social em relação a pretensões de "preenchimento" do sujeito, ou seja, daquilo que permanece de indiscernível e indeterminado no campo da subjetividade, mas não por isso deixa de atuar de algum modo ${ }^{32}$. Lembremos que, para Lacan, o Real seria inassimilável pela linguagem, mas ainda assim atuaria de maneiras distintas - dissolvendo imagens, desorganizando o campo do simbólico e, principalmente, produzindo estranhamento. Ainda que escape à linguagem, o "Real" não deixa de atuar. O resquício do seu potencial normativo parece residir justamente em colocar os limites da normatividade, em diagnosticar o que atua e que produz a subversão da norma ${ }^{33}$.

32 Cf. PACHECO, 2016.

${ }_{33}$ Tenho em mente aqui articulações entre psicanálise e teoria social tais como propostas por autores como Alain Badiou, Slavoj Zizek, Judith Butler e Vladimir Safatle. Cabe lembrar que a recepção da psicanálise ao longo das diferentes tradições da teoria crítica refere-se quase que exclusivamente ao freudismo - seja na sua formulação original, ou nas correntes revisionistas. 0 papel das abordagens psicanalíticas como as de Jacques Lacan, Melane Klein e Jean Laplanche - passam praticamente despercebidas, sem, muitas vezes, encontrarmos uma justificativa satisfatória para tal recusa teórica. Certamente, as reservas diante da teoria lacaniana mostram-se como um dos exemplos mais paradigmáticos, dada a sua ampla influência em outras tradições filosóficas, apenas para mencionar 
Em relação a este problema persistiria, ao meu ver, a questão de em que medida uma teoria social é capaz de interferir em aspectos que envolvem o âmbito do que Lacan chamou de Real, e que sequer pode ser simbolizado. Pois, ainda que concordemos com um possível caráter de atuação daquilo que não pode ser simbolizado e esgotado pela linguagem, seria infrutífero reenquadrar a teoria social a partir de sentidos como estranhamento - o que, de resto, nos recolocaria nas já mencionadas aporias de um inflacionamento de categorias psicanalíticas ao âmbito de uma teoria social normativa. Talvez a melhor expressão desse limite recíproco entre teoria social e psicanálise seja o conhecido aforismo com o qual Wittgenstein conclui o seu Tractatus: "sobre o que não se pode falar, deve-se calar". É provável que o sentido lacaniano do Real esteja justamente além desse limite, apontando para uma indiscernibilidade no âmbito de uma teoria social. Contudo, ainda que não se negligencie os efeitos da atuação de um real indiscernível, a teoria social "deve calar" sobre esse âmbito, simplesmente porque ela não pode falar sobre ele. Uma pluridimensionalidade do sujeito refere-se, portanto, não somente ao sentido de "negatividade" - ou seja, daquilo que escapa às relações intersubjetivas -, como também à contingência dessas relações, e que não se coloca nos termos de uma crítica a uma teoria social. Sentido análogo a quando Adorno escreve que "toda imagem de ser humano é ideologia, exceto a negativa" (2015a, p. 103).

É aqui que entendo como tendo lugar o papel da clínica: ela parece assumir um significado terapêutico que não compete a teorias sociais, e que se volta para o que escapa a esta dimensão intersubjetiva. Trata-se, em última análise, de lidar de maneira produtiva com o conflito, com a indeterminação, sem ultrapassar os limites daquilo apreensível pela teoria. Adorno escrevera que a identidade não pode ser concebida como totalidade harmoniosa e unificada, mas como "um sistema de cicatrizes, que somente poderiam ser integradas sob sofrimento" (2015b, p. 48). A terapia do sofrimento não deve obstruir aquilo que possui de constitutivo, inevitável e produtivo, deixando indeterminados os espaços de constituição do desejo, em um sentido terapêutico mais consequente, talvez próximo ao que Hegel tinha em vista quando escreve que "as feridas do espírito curam sem deixar cicatrizes" (HEGEL, 2012, p. 455). O inflacionamento de âmbitos de determinação da

alguns. Apenas esforços mais recentes, em todo o caso mais heterodoxos às principais contribuições na esteira da teoria crítica stricto senso, propõem uma aproximação da abordagem lacaniana - como nos autores mencionados acima. Apesar de não poder, aqui, entrar em detalhes sobre essas diferentes interpretações, pretendo discutir melhor esse problema em um possivel desdobramento do presente artigo. 
subjetividade, inibição a todo custo de um sofrimento inexaurível, parecem ser as formas mais contraproducentes de se pensar a relação entre subjetividade na sua indissociabilidade de contextos socialmente mediados.

Já um terceiro tipo de sofrimento, decorrente do próprio processo de subjetivação, nem a aposta em um conteúdo normativo da teoria social nem o papel da clínica psicanalítica parecem ser capazes de resolver. Pôr um limite é reconhecer que há algo além dele - ainda que, nem do ponto de vista da teoria psicanalítica e tampouco da teoria social, seja possível esgotar o seu conteúdo.

\section{Referências}

ADORNO, T. W. Minima Moralia. São Paulo: Ática, 1993. . "Sobre a relação entre sociologia e psicologia". In: . Ensaios sobre psicologia social e psicanálise. São Paulo: Editora Unesp, 2015a.

. "A psicanálise revisitada". In: . Ensaios sobre psicologia social e psicanálise. São Paulo: Editora Unesp, $2015 \mathrm{~b}$.

. "Observações sobre política e neurose". In: . Ensaios sobre psicologia social e psicanálise. São Paulo: Editora Unesp, 2015c. ; FRENKEL-BRUNSWIK; et all. The Authoritarian Personality. New York: Harper \& Row, 1950.

ALLEN, A. "Are We Driven? Critical Theory and Psychoanalysis Reconsidered”. In: Critical Horizons, v.16, Issue 4, 2015.

CAMPELLO, F. "Do reconhecimento à liberdade social: Sobre 'O direito da liberdade', de Axel Honneth". In: Cadernos de Ética e Filosofia Política (USP), v. 2, p.186-197, 2014.

. Die Natur der Sittlichkeit. Grundlagen einer Theorie der Institutionen nach Hegel. Bielefeld: Transcript. 2015.

DUNKER, C. “Apresentação à edição brasileira”. In: ADORNO, T. W. Ensaios sobre psicologia social e psicanálise. São Paulo: Editora Unesp, 2015.

EHRENBERG, A. La fatigue d'être soi. Dépression et société. Paris: Odile Jacob, 1999.

PACHECO, M. "Honneth e a pulsão: sobre as razões e as consequências para a crítica social da rejeição honnethiana à pulsão de morte freudiana". In: Psicologia USP, v.27, n.1, São Paulo, jan./abr. 2016. 
FRASER, N. “Reconhecimento sem ética?” In: Lua Nova. São Paulo, 70, 2007, p. 101-138.

FREUD, S. Gesammelte Werke, V. V. Frankfurt: Fischer, 1999.

FROMM, E. O medo à liberdade. Rio de Janeiro: Guanabara, 1986.

- Die psychoanalytische Charakterologie und ihre Bedeutung für die

Sozialpsychologie. Zeitschrift für Sozialforschung, Bd. 1, 1932, p. 253-277.

HABERMAS, J. "A Filosofia como Guardadora de Lugar e como Intérprete”. In: . Consciência Moral e Agir Comunicativo. Rio de Janeiro: Tempo

Brasileiro, 1989.

. Pensamento pós-metafísico. Estudos Filosóficos. Rio de Janeiro: Tempo

Brasileiro, 1990.

HEGEL, G. W. F. Enciclopédia das ciências filosóficas em compêndio. 3 vol. São

Paulo: Loyola, 1995.

. Fenomenologia do espírito. Petrópolis: Vozes, 2012.

HONNETH, A. Kritik der Macht. Reflexionsstufen einer kritischen Gesellschaftstheorie. Frankfurt am Main: Suhrkamp, 1985.

. "Recognition: Invisibility: On the epistemology of 'recognition". In:

Aristotelian Society Supplementary, 75 (1), p.111-126, 2001.

2003.

. Luta por reconhecimento: a gramática dos conflitos sociais. São Paulo: 34,

. "Objektbeziehungstheorie und postmoderne Identität: über das

vermeintliche Verhalten der Psychoanalyse". In:

Unsichtbarkeit: Stationen einer Theorie der Intersubjektivität. Frankfurt am Main:

Suhrkamp, 2003b, p.138-161.

. "Organized Self-Realization: some paradoxes of individualization".

In: European Journal of Social Theory, p.463-478, 2004.

. Sofrimento de indeterminação. São Paulo: Esfera Pública, 2007a.

. Pathologien der Vernunft. Geschichte und Gegenwart der Kritischen Theorie.

Frankfurt am Main: Suhrkamp, 2007b.

. Reification. Oxford: Oxford University Press, 2008.

. "Von der Begierde zur Anerkennung". In: . Das Ich im Wir,

Berlin: Suhrkamp, 2010, p. 15-32. 
. Das Recht der Freiheit. Grundriß einer demokratischen Sittlichkeit. Berlin:

Suhrkamp, 2011.

. “O eu no nós: reconhecimento como força motriz de grupos". In:

Sociologias, Porto Alegre, ano 15, n.33, p.56-80, mai./ago. 2013.

. "Diseases of Society: Approaching a Nearly Impossible Concept". In:

Social Research, v. 81, n. 3, p.683-703, 2014.

; RÖSSLER, B. Von Person ₹u Person. Zur Moralität persönlicher

Beziehungen. Frankfurt am Main: Suhrkamp, 2008.

JAY, M. A imaginação dialética. História da Escola de Frankfurt e do Instituto de Pesquisas Sociais, 1923-1950. Rio de Janeiro: Contraponto, 2008.

LACAN, J. Le séminaire livre XXIII, Le sinthome. Paris: Éditions du Seuil, 2005.

LEAR, J. Love and its place in nature. A philosophical interpretation of Freudian psychoanalysis. New Haven: Yale University Press, 1999.

MARIN, I. L. "Psicanálise e emancipação na teoria crítica". In: Marcos, Nobre (org.), Curso livre de teoria crítica. Campinas: Papirus, 2008.

MARCUSE, H. Eros e civilização: Uma interpretação filosófica do pensamento de Freud. Rio de Janeiro: Zahar, 1981.

NEUHOUSER, F. Foundations of Hegel's social theory. Actualizing freedom.

Cambridge, MA: Harvard University Press, 2000.

SAFATLE, V. O circuito dos afetos. São Paulo: Cosac Naify, 2015.

E-mail: filipebcampello@gmail.com

Recebido em: 02/2017

Aprovado em: 09/2017 